\title{
On the relevance of cartography - An interaction design perspective
}

\author{
Sebastian Meier $^{\mathrm{a}}{ }^{*}$, Jordi Tost ${ }^{\mathrm{b}}$, Frank Heidmann ${ }^{\mathrm{b}}$ \\ ${ }^{a}$ Technologiestiftung Berlin, meier@technologiestiftung-berlin.de \\ ${ }^{b}$ University of Applied Sciences Potsdam, jordi.tost.val@fh-potsdam.de,heidmann@fh-potsdam.de \\ * Corresponding author
}

\begin{abstract}
We see more cartographic products in our digital world than ever before. But what role does cartography play in the modern production of cartographic products? In this position paper, we will argue that the democratization and diffusion of cartographic production has also led to the presumed "fading relevance" of cartography. As an argument against this notion, we highlight starting points for the field of cartography to improve modern cartographic production through its inherent cartographic knowledge.
\end{abstract}

Keywords: Cartography, Interaction Design, Human-Computer Interaction, Geovisualization, Research Challenges

\section{Introduction}

Over the last two decades, the cartographic community has experienced a democratization of digital spatial technologies and information. This trend was strongly driven by web cartography, which led to novel web-based cartographic tools for data processing and representation, in many instances even available as open source software (see e.g. Mapbox, D3, turf.js or Mapbender). In addition, national and regional open data programs, as well as volunteer geographic data infrastructures, such as OpenStreetMap (OSM), are providing citizens, researchers and companies with access to a variety of publicly available spatial information resources. Besides immense innovation in the expert field of spatial research and spatial industries, those trends changed the relationship between consumers and producers of cartographic products ${ }^{1}$. Before, the production of most cartographic products was in the hands of cartographic experts, who were producing for a consumer audience. Through the availability of tools and data, we see a diffusion of cartographic production. Non-experts or experts from other domains - like interaction design ${ }^{2}$, digital humanities or journalism - or even traditional

\footnotetext{
${ }^{1}$ When we mention cartographic products, this includes maps, geovisualizations and other interfaces to spatial information, across systems and devices.

${ }^{2}$ Interaction design is more than a domain; it is an embedded practice across multiple domains: from design to humancomputer interaction (HCI), to human factors, to information visualisation. It also encompasses other definitions like interface design or user experience design. The terminology emerged in the 1980s and early 1990s (Moggridge \& Atkinson 2007; Verplank 2013; Norman 2013). It is concerned with "the practice of designing interactive digital products, environments, systems, and services" (Cooper et al., 2007) as well as their visual representations and interfaces, and their inherent principles of interaction.
}

consumers, are suddenly producing their own maps, through infrastructures like OpenStreetMap (OSM) and web-based mapping services (e.g. Mapbox or Carto). Consumers are also producing spatial information, passively through location-based services like Foursquare, Pokémon Go and Google Maps or actively by voluntarily providing their location information through geographic information systems like OSM, geotagged photo services like Flickr and Instagram, and in geo-referenced social media posts from Facebook and Twitter. All those developments led to more spatial data and cartographic applications and products.

As more and more actors entered the field of cartographic production, it initiated a discussion on the relevance of traditional cartography as a discipline and a practice. Many experts have joined the discourse in recent years (Çöltekin et al., 2017; Griffin et al., 2017; Kraak and Fabrikant, 2017; Roth, 2015; Robinson et al., 2017; Gartner, 2013a; 2013b; 2015). The former president of the International Cartographic Association (ICA) Georg Gartner, has been addressing this issue for years, particularly under his presidency (see e.g. Gartner, 2013a; 2013b; 2015). In their 2017 paper, Çöltekin et al. report their findings from exchanges between 72 experts from "various sub-domains of geographic information science and technology" on persistent challenges in geovisualization (Çöltekin et al., 2017). The first of three persistent challenges identified from their research is to create "a better understanding of the scope of our domain, how it interacts with other domains, and how to make this happen". This aspect of interdisciplinarity, as highlighted by Çöltekin et al., presents the cartographic community with as much potential as it confronts them with challenges. This notion is also present in the other papers on cartography's relevance mentioned above. Especially in the challenges framed as "challenges of interdisciplinarity", such as "accessibility, popularity and dissemination" (Çöltekin et al. 2017), we see the 
opportunity for cartography to regain relevance. On this basis, we question the prevalent notion of cartography's fading relevance in order to start a discussion on new, future perspectives for cartography, particularly at the intersection with other domains. Our discussion centers on the intersection of cartography and interaction design.

\section{Related Work}

As interactive digital products have become ubiquitous in many aspects of our daily lives, digital map products embedded in many of such systems have also become ubiquitous. The design of interactions in map-based interfaces and geovisualizations requires insight from cartographic knowledge. The importance of the humancomputer interfaces to digital cartographic products and their inherent interactions has also been acknowledged by the cartographic community (e.g., MacEachren and Kraak, 1997; Cartwright et al., 2001; MacEachren and Kraak, 2001; Dykes, 2005; Andrienko et al., 2007; MacEachren, 2013). Similar to our discussion, the importance of the intersection between the fields of interaction design and cartography was also extensively discussed by Roth in his 2015 paper (Roth, 2015). Following his findings from interviews with 21 geospatial professionals, he frames these intersections as "cartographic interactions". Through the perspectives presented in this paper, we want to build upon Roth's work and share further insights into the intersection between cartography and interaction design, from both an academic and practice-based interaction design point of view. Roth worked towards answers to the following questions: "(1) what is cartographic interaction; (2) why provide cartographic interaction, (3) when should cartographic interaction be provided, (4) who should be provided with cartographic interaction; (5) where should cartographic interaction be provided; and (6) how should cartographic interaction be provided?" (Roth, 2015). In contrast to Roth's results, we are more interested in how perspectives from interaction design might inform discussions on how cartography can regain relevance.

\section{A new relevance for cartography}

Kraak and Fabrikant note how historically, some cartographic innovations have come from "outsider" disciplines, by map makers that were not trained cartographers (Kraak and Fabrikant, 2017). Following this line of thought, the following sections present our interaction design perspectives on four elements of cartographic production, and how the status quo might be improved through cartographic knowledge. And, thereby, show starting points for Çöltekin's challenges of increasing cartographic knowledge's "accessibility, popularity and dissemination".

\subsection{The Design of Cartographic Products}

The diffusion of map-making technologies has brought about a variety of services and tools, allowing users that are not cartographic experts to produce maps. Today, maps can be created almost instantaneously, transforming the process of cartographic mapping and visualisation into a fast, convenient, and sometimes semi-automatic process. Mapping services like Carto or Mapbox - and even Google Maps - provide high-level frameworks for designing maps and visualizing spatial data. The design process, from data processing to selecting visual representations for spatial data, has become convenient and is little reflected upon, neglecting valuable, longestablished cartographic rules and knowledge. This trend often becomes apparent in two extremes. On the one hand, most of the modern tools have predefined visual variables, map types, projections and styles, and while there is some room for customization, the results tend to be generic and lack intentionally applied thematic map design principles. On the other hand, some products allow more customization, and thereby introduce other challenges, such as aesthetics-precision trade offs. Aesthetics do play a fundamental role in attracting viewers' attention and engaging them (Cawthon and Vande Moere, 2007), not only for casual users (Nagel et al., 2014), but also experts alike (Anwar et al., 2014). Also from the cartography perspective, "map displays should be well designed, and attractive to look at. In other words, maps that matter should raise interest, be engaging, instantly understandable and relevant to society" (Kraak and Fabrikant, 2017). But if the aesthetics are not also informed by cartographic knowledge, in many cases conflicts between beauty and readability or aesthetics and interpretation can arise. Therefore, creators of cartographic products need to understand the importance of thematic cartography and cartographic design principles.

Seeing cartographic products not only as tools, but as instruments and representations of power (Crampton et al., 2005), we highly value the democratization of cartographic information and tools, while we also see a drop in standards and quality. Therefore, we believe, the cartographic community needs to also take the needs of new map producers into account, help them to easily create their cartographic products, find ways to diffuse cartographic knowledge in those new domains, and improve the tools used to build such products.

\subsection{Cartographic products beyond the static map}

The primary aspects of cartography are located in the triangle of data, technology and design (Gartner and Huang, 2016). Design in cartography has been considered as the "most fundamental, challenging and creative aspect of the cartographic process" (De Lucia, 1974, 83). Through novel designs of cartographic products, we are enabling people to understand complex situations: "Cartographic communication processes and maps (or map-like products) are the keys to enable humans to efficiently deal with all kinds of spatial data" (Gartner and Huang, 2016). The aforementioned tools (Mapbox, Carto, etc.), that are readily available, are often good starting points for such spatial explorations, but depicting data on a map is often not enough. Tools need to be extended to allow users to adopt novel and innovative spatial data visualisation and exploration techniques. A 
good example from outside the traditional stream of cartographic products can be found in interaction design and data-driven journalism.

An application example for such products is illustrated in figure 1. The interface shows an approach for exploring reachability of remote areas through visualization with an interactive tabletop and tablets for a case study of landslide threat (Tost and Heidmann, 2017). Guided by requirements from the users, the interaction model is kept simple through use of cartography's concepts of generalisation.
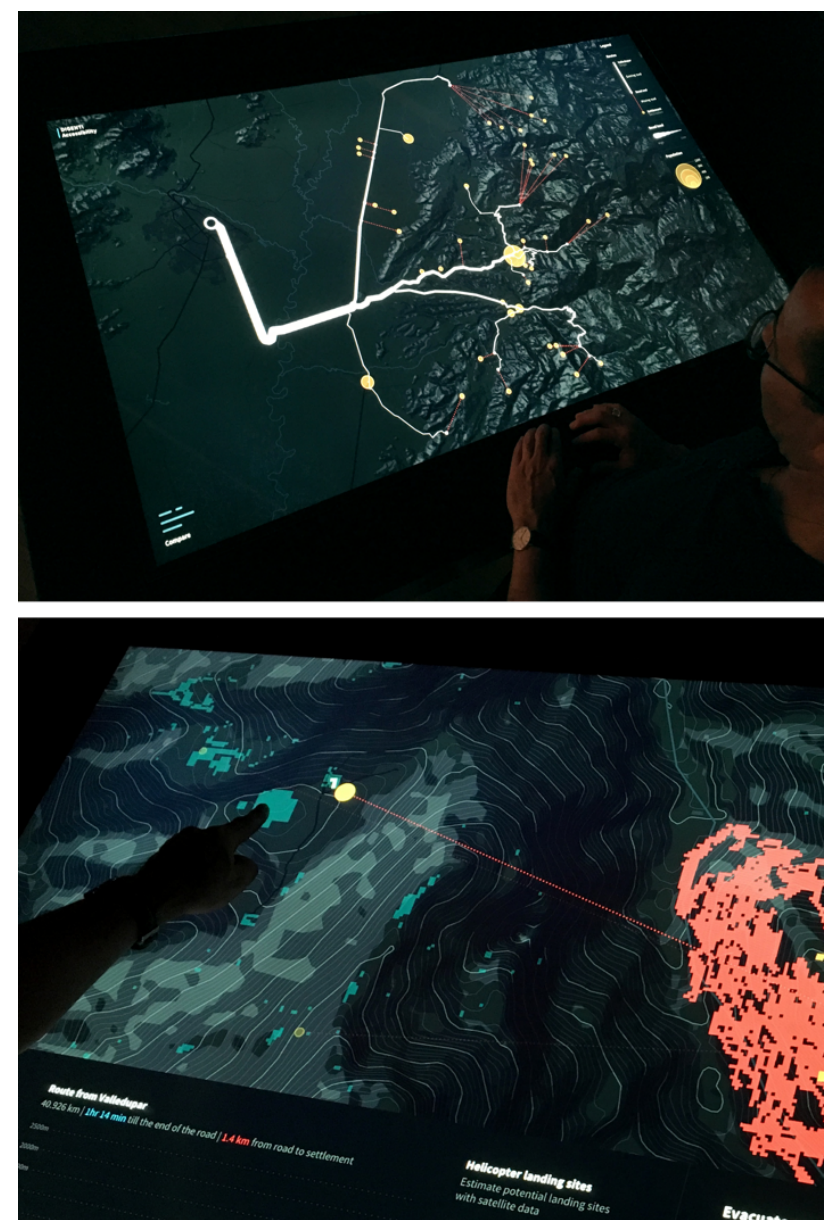

Figure 1. Tost et al. designed the system with only two interactive states: area overview, and settlement detail on demand. The area overview (top) provides a fast situation overview through non-standard visualization techniques. This view allows users to gain insights on the general reachability of the entire study area at a glance, with no interaction needed. On demand, the interface gives detailed information on the reachability of a particular settlement or area (bottom).

\subsection{Cartographic knowledge}

The previous two sections focused on practical and applied approaches. In addition to those approaches, there is a whole range of theoretical cartographic knowledge, of which many non-cartographer users are unaware and which are also not present in most digital ready-made cartographic products. Underlying most of those is the most important cartographic principle: that maps are an abstraction of reality (Gartner, 2013b) and thus, processes of abstraction and generalisation are fundamental for designing maps and visualizations, and shaping the user's views on the world. This principle is especially important in order to cope with data congestion and information overload when working with complex datasets from multiple heterogeneous sources (Tost et al., 2018).

A prominent, long-discussed example is map projections. While there are many projections optimised for various use cases, the most used projection in digital map products on the web is still the Mercator projection. This example also illustrates how the packaging of cartographic knowledge in accessible technologies can lead to better dissemination of such knowledge. The JavaScript library D3 (Bostock, 2019), one of the most used visualisation libraries on the web, has made it extremely easy to use a whole variety of projections (see figure 2), which has led to more variety in projection usage, going beyond the Mercator projection. This implementation is exemplary for how to bring cartographic knowledge into use in order to cartographic products.

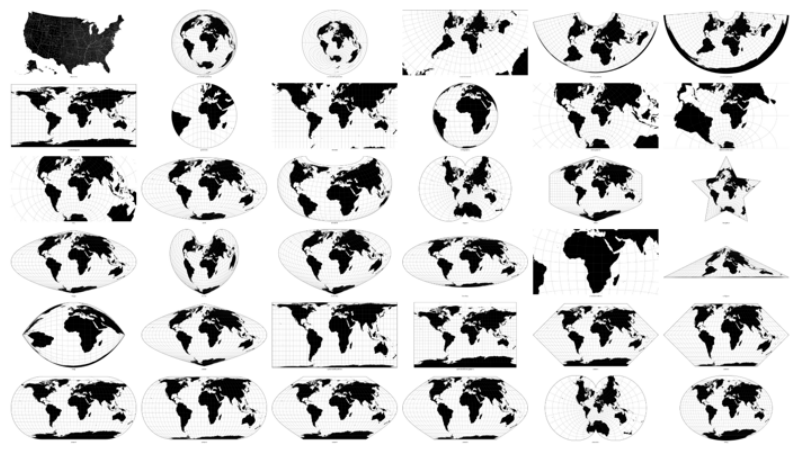

Figure 2. Some map projections visualized using the JavaScript library d3.js (Bostock, 2019).

\subsection{Co-creation and user-centered design}

In some ways, cartography was very user-centered before this became a trend in other domains. Following the cartographic communication model (Heidmann 2013, MacEachren 2004), cartography is about finding representations for spatial information, which should include the reader's perception and understanding of that product. Therefore, the differences and needs among cartographic product users should define how we design them, or as Griffin et al. pointed out: "The full spectrum of diversity plays a crucial role in shaping what is mapped and how it is mapped today" (Griffin et al., 2017). While there is a strong notion of "user-centricity", we believe that cartography has not yet fully embraced methods and techniques of co-creation and user-centered design. Cartography uses usability testing methods, like eye tracking, for the evaluation of maps. But this evaluation is often performed at the end of the design process, in order to help improve the end product, like a map design. But, user-centered design methods are rarely used in the beginning, to focus research on relevant topics and needs of the actual users. While cartographers are still the cartographic experts, the diffusion of cartographic tools (of production) requires us to learn 
more about the variety of user groups, in order to gain insights about these users' needs and requirements (Züllighoven et al., 2018). In this regard, cartography could explore techniques from fields like interaction design in order to learn about modern user-centric design perspectives.

\section{Future Challenges}

The previous section primarily looked at the current production of cartographic products and possible starting points for improving those processes by increasing the "accessibility, popularity and dissemination" of cartographic knowledge. (Çöltekin et al., 2017). Before we come to the closing discussion, we want to highlight a few future challenges from the interdisciplinary perspective at the intersection of cartography and interaction design.

\subsection{Designing for Big Data}

One of the research questions suggested in a recent study by Griffin et al. (2017) by ICA Commission Members for the future of cartographic research is: "Maps have a potential role to play in big data analysis, we need to know which map representations are suitable as summary maps of big data? How can map design be improved to become an interface to big data?". With trends like autonomous cars, unmanned aerial vehicles (UAVs), growing numbers of satellites producing spatial information or volunteered cartographic information, the amount of spatial information is continuously growing. Cartographic products can become interfaces to complex spatial data, and depictions of complex heterogeneous datasets. Particularly novel interactive cartographic tools will be required, which may help to "make sense of geospatial big data” (Robinson et al. 2017).

\subsection{Machine Learning}

Strongly connected to big data, the attention gaining domain of machine learning and artificial intelligence will also become more important for the cartographic domain. From new approaches for map design and map production (Kogan et al 2016), to methods and techniques of data analysis. Outside the cartographic domain, growing research on machine learning in the information visualisation community could inspire future use cases for cartographic research and practice (see e.g. Zhang et al 2019, Sacha et al 2019, M. El-Assady 2019). A trend visible at last year's IEEE VIS conference were interfaces and systems that would either visualise the inner workings of machine learning systems or help users control the learning process. Understanding principles of machine learning and their influence on the cartographic practice will be of importance in order the shape this influence.

\subsection{New devices, new media}

On a physical level, we see more and more devices capable of displaying maps and allowing interactions with them. This makes maps even more ubiquitous. Therefore, it is crucial to understand how to design cross- device cartographic products and interfaces, which can be tangible, embodied (e.g. wearables or smart watches) or a software interface (e.g. computer screens, smartphones and tablets, interactive tabletops, surfaces or walls, and virtual or augmented reality environments). Furthermore, the design of interactions can be revealed in different modalities (e.g. multi-modal interaction). Interacting with maps is now possible with multiple devices and multiple senses, and this may involve different users in different locations, who may interact alone or collaborate with others around or through a map (Tost and Heidmann, 2017). Exploring how cartography can purposefully inform the design of such systems and interactions could potentially lead to more meaningful interactions and systems.
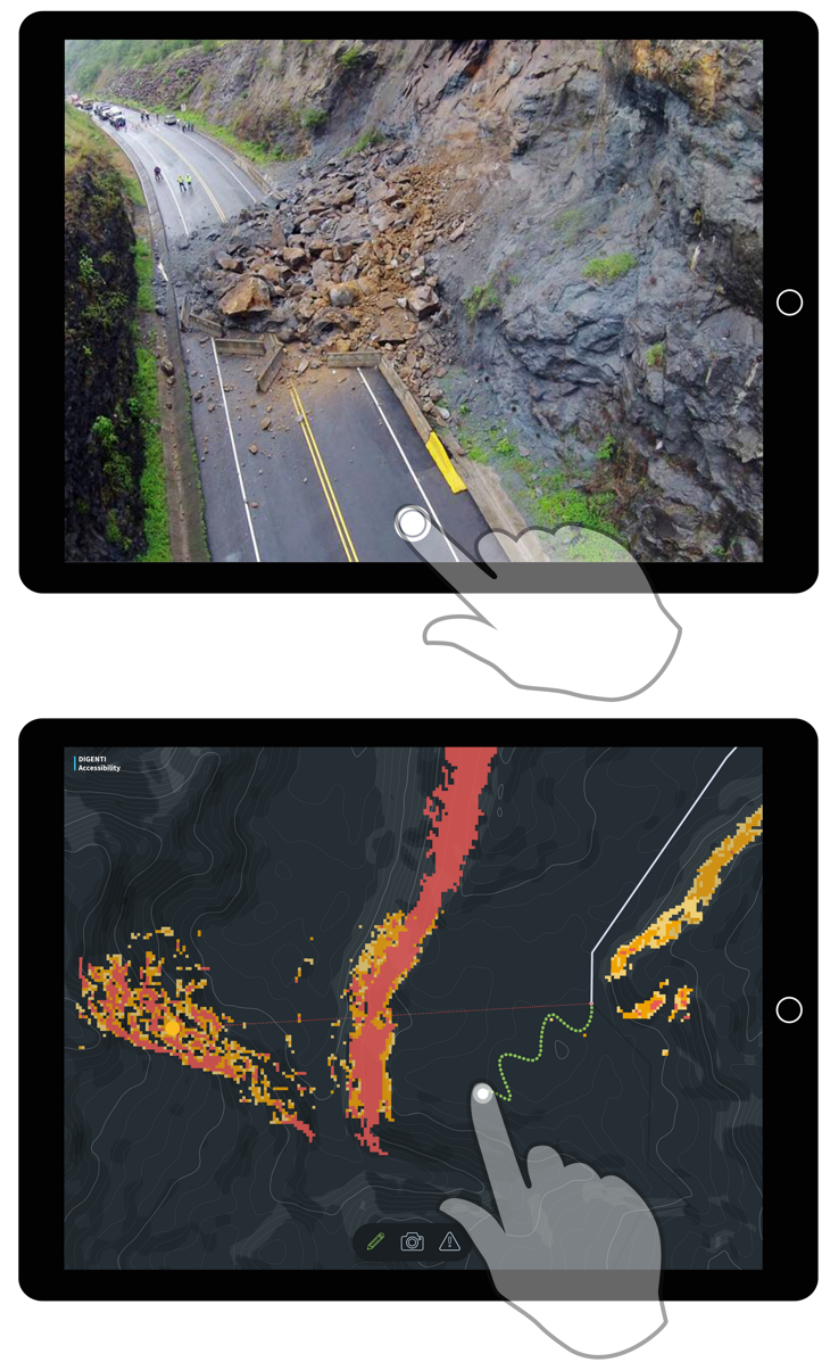

Figure 3. Our system (see also figure 1) was designed to enable stakeholders to collaborate in emergency planning situations. A tablet interface allows stakeholders on the field to validate and report (top), and to do manual mapping of alternative off-road paths through free-form sketching (bottom). Simultaneously, decision makers in the control room are able to access the data on the interactive tabletop (figure 1) (Tost and Heidmann 2017). 


\section{Summary and Discussion}

Kraak and Fabrikant (2017) point out, "a resilient and forward looking discipline has to continue to be inclusive, innovative and open to change, so that we can keep handling societal and technological transformations, without compromising on fundamental cartographic values". With debate about the relevance of cartography in mind, in this position paper we followed up the thoughts of Kraak and Fabrikant and explored the intersection of cartography and interaction design. As this is a position paper, our arguments are based upon literature review, but also informed by our year-long experience in interaction design research, practice and, most importantly, teaching. In teaching, we see an increasing need for more "accessibility, popularity and dissemination" (Çöltekin et al., 2017) of cartographic knowledge, in order to address the challenges and opportunities outlined in this paper. As starting points for the discussion, we highlighted the following:

- Map Design: disseminate cartographic design knowledge, content- and reader-centric design of maps that goes beyond generic standardised maps.

- $\quad$ Aesthetic-Precision trade off: balancing aesthetic requirements with cartographic accuracy

- Beyond the map: cartographic interfaces and visualisations that go beyond traditional static maps.

- Cartographic Knowledge: Critical understanding of maps, their inherent power and how to include this in the design and development process.

- Co-Creation and User-centered design: Emphasizing the role of the reader/user and including them in the production process, from start to end.

The continuously progressing digitisation of the field will lead to more data- and algorithm-centric methods, requiring researchers as well as practitioners to acquire new skills in this area:

- Big Data: As more and more data is available, new methods for processing, storing and analysing large amounts of spatial data are required.

- Machine Learning: Within the prior challenge the importance of automated and semiautomated techniques for processing, storing and analysing large amounts of spatial will grow.

- Uncertainty: Visualising and communicating uncertainty for spatial data.

- New devices, new media: bringing maps and cartographic interfaces to new devices like smart watches or augmented reality.
Through the points highlighted above, we showed the prevailing relevance of cartography, particularly of cartographic knowledge. We believe that further improving the "accessibility, popularity and dissemination" of this knowledge is of utter importance in order to increase the relevance of the cartographic discipline. We hope that this paper inspires discussion on the future of cartography and that it the arguments for the importance and relevance of cartography.

\section{Attribution}

Jordi Tost's research on the project DIGENTI (Tost and Heidmann, 2017; Tost et al., 2018) was funded by the German Federal Ministry for Economic Affairs and Energy (BMWi) within the INNOspace initiative of the German Aerospace Center (DLR). Jordi Tost is currently working on the project PROTOTYP, supported by the funding line "Language of Objects - Material Culture in the Context of Social Developments" of the German Federal Ministry of Education and Research (BMBF). Sebastian Meier is working as the lead data scientist for the Technologiestiftung Berlin, which is supported by the Senatsverwaltung für Wirtschaft, Energie und Betriebe and the Investitionsbank Berlin using funds from the Land Berlin.

\section{References}

Anwar, A., Nagel, T., \& Ratti, C. (2014, March). Traffic origins: A Simple Visualization Technique to Support Traffic Incident Analysis. In Visualization Symposium (PacificVis), 2014 IEEE Pacific (pp. 316-319). IEEE.

Bertin, J., Berg, W. J., \& Wainer, H. (1983). Semiology of graphics: diagrams, networks, maps (Vol. 1, No. 0). Madison: University of Wisconsin press.

Bostock, Mike (2019) D3 - https://d3js.org. Last accessed 25.03.2019

Cawthon, N., \& Vande Moere, A. (2007, July). The effect of aesthetic on the usability of data visualization. In Information Visualization, 2007. IV'07. 11th International Conference (pp. 637-648). IEEE.

Crampton, J. W., \& Krygier, J. (2005). An introduction to critical cartography. ACME: An International Journal for Critical Geographies. 4 (1): 11-33. ISSN 14929732.; Wood, Denis. 1992. The Power of Maps, New York/London, The Guilford Press.

Çöltekin, A., Bleisch, S., Andrienko, G., \& Dykes, J. (2017). Persistent challenges in geovisualization-a community perspective. International Journal of Cartography, 3(sup1), 115-139.

El-Assady, M., Sperrle, F., Deussen, O., Keim, D., \& Collins, C. (2019). Visual Analytics for Topic Model Optimization based on User-Steerable Speculative Execution. IEEE transactions on visualization and computer graphics, 25(1), 374-384.

Elmqvist, N., Vande Moere, A., Jetter, H. C., Cernea, D., Reiterer, H., \& Jankun-Kelly, T. J. (2011). Fluid interaction for information visualization. Information Visualization, 10(4), 327-340. 
Gartner, G. (2013a) It's OK to be a Cartographer!, President's Blog ICACI.org, International Cartographic Association, accessed on 01.12.2018 https://icaci.org/presidents-blog-its-ok-to-be-acartographer/ (Article has also been published in GIM INTERNATIONAL - JANUARY 2014)

Gartner, G. (2013b) The Relevance of Cartography in arcNews 2013/14, accessed 01.12.2018 http://www.esri.com/esri-

news/arcnews/winter1314articles/the-relevance-ofcartography

Gartner, G. (2015) The International Cartographic Association 2011 - 2015 Report of the President, International Cartographic Association

Griffin, A. L., Robinson, A. C., \& Roth, R. E. (2017). Envisioning the future of cartographic research. International Journal of Cartography, 3(sup1), 9-31.

Heidmann, F. (2013). Interaktive Karten und Geovisualisierungen. In Interaktive Infografiken (pp. 39-69). Springer Vieweg, Berlin, Heidelberg.

Kinkeldey, C., MacEachren, A. M., \& Schiewe, J. (2014). How to assess visual communication of uncertainty? A systematic review of geospatial uncertainty visualisation user studies. The Cartographic Journal, 51(4), 372-386. ISO 690

Kogan, G., Gambotto, G., Samsen, A., Boleslavský, A., Ferretti, M., Gui, D., Frei, F. (2016) Invisible Cities. Made during Machine learning for artists workshop at OpenDot, 21-25 November 2016. https://opendot.github.io/ml4a-invisible-cities/

Kraak, M. J., \& Fabrikant, S. I. (2017). Of maps, cartography and the geography of the International Cartographic Association. International Journal of Cartography, 3(sup1), 9-31.

MacEachren, A. M. (2004). How Maps Work. Guilford Press.

MacEachren, A. M., Robinson, A., Hopper, S., Gardner, S., Murray, R., Gahegan, M., \& Hetzler, E. (2005). Visualizing geospatial information uncertainty: What we know and what we need to know. Cartography and Geographic Information Science, 32(3), 139-160.

MacEachren, A. M., Roth, R. E., O'Brien, J., Li, B., Swingley, D., \& Gahegan, M. (2012). Visual semiotics \& uncertainty visualization: An empirical study. IEEE Transactions on Visualization and Computer Graphics, 18(12), 2496-2505.

Moggridge, B., \& Atkinson, B. (2007). Designing interactions (Vol. 17). Cambridge, MA: MIT press.

Nagel, T., Maitan, M., Duval, E., Vande Moere, A., Klerkx, J., Kloeckl, K., \& Ratti, C. (2014, May). Touching Transport - A Case Study on Visualizing Metropolitan Public Transit on Interactive Tabletops. In Proceedings of the 2014 International Working Conference on Advanced Visual Interfaces (pp. 281288). ACM.

Norman, D. (2013). The design of everyday things: Revised and expanded edition. Constellation.
Robinson, A. C., Demšar, U., Moore, A. B., Buckley, A., Jiang, B., Field, K., ... \& Sluter, C. R. (2017). Geospatial big data and cartography: research challenges and opportunities for making maps that matter. International Journal of Cartography, 3(sup1), 32-60.

Roth, R. (2015). Interactivity and cartography: A contemporary perspective on user interface and user experience design from geospatial professionals. Cartographica: The International Journal for Geographic Information and Geovisualization, 50(2), 94-115.

Roth, R., Ross, K., \& MacEachren, A. (2015). Usercentered design for interactive maps: A case study in crime analysis. ISPRS International Journal of GeoInformation, 4(1), 262-301.

Sacha, D., Kraus, M., Keim, D. A., Chen, M., (2019). VIS4ML : An Ontology for Visual Analytics Assisted Machine Learning. In: IEEE Transactions on Visualization and Computer Graphics. 25(1), pp. 385395. ISSN 1077-2626. eISSN 1941-0506.

Shea, K. S., \& McMaster, R. B. (1989). Cartographic generalization in a digital environment: When and how to generalize. In Proceedings for Auto-Carto (Vol. 9, pp. 56-67).

Shneiderman,B.(1996).The eyes have it: A task by data type taxonomy for information visualizations. In Visual Languages, 1996. Proceedings., IEEE Symposium on (pp. 336-343). IEEE.

Tost, J., \& Heidmann, F. (2017). Visualization and Interaction with Multiple Devices. A Case Study on Reachability of Remote Areas for Emergency Management. i-com, 16(3), 223-246.

Tost, J., Ehmel, F., Heidmann, F., Olen, S. M., \& Bookhagen, B. (2018). Hazards and accessibility: combining and visualizing threat and open infrastructure data for disaster management. Proceedings of the ICA, Volume 1, 2018, pp. 115, 1, 115.

Verplank, B. (2003). Interaction design sketchbook. Unpublished paper for CCRMA course Music 250a.

Zhang, J., Wang, Y., Molino, P., Li, L., \& Ebert, D. S. (2019). Manifold: A Model-Agnostic Framework for Interpretation and Diagnosis of Machine Learning Models. IEEE transactions on visualization and computer graphics, 25(1), 364-373.

Züllighoven, H., Nitschke, J., Reiswich, E., Kowalczyk, M., \& Schwentner, H. (2018). Vom Design digitaler Arbeitsgegenstände: Planung des Schiffverkehrs im Hamburger Hafen mit dem Peiltisch. Mensch und Computer 2018-Usability Professionals. 